\title{
Historia magistra vitae e imitación: la ejemplaridad política de las historias en Maquiavelo
}

\author{
María Belén CASTAÑÓN MORESCHI \\ Texas A\&M University \\ mbcmoreschi@tamu.edu
}

\begin{abstract}
RESUMEN
Este trabajo analiza el desarrollo del topos ciceroniano historia magistra vitae en la obra de Nicolás Maquiavelo en la medida en que pone en juego un concepto de historia ajeno al papel didáctico-moralizante de la tradición humanista, de tal modo que la ejemplaridad de las historias se revela como un elemento esencial para la configuración de un arte dello stato. Esta formulación del lugar común se encuentra en la obra del florentino ligada a la aproximación crítica a la imitación de los tiempos antiguos y de los ejemplos recogidos en las historias a través de una doble articulación que le sitúa en una postura ecléctica entre clasicismo y novedad.
\end{abstract}

PALABRAS CLAVE: Maquiavelo, historia magistra vitae, Koselleck, imitación, ejemplaridad, fortuna, ocasión.

\begin{abstract}
This paper analyzes the development of the Ciceronian topos historia magistra vitae in the work of Niccolò Machiavelli in so far as it brings into play a concept of history which is not involved in the didactic-moralizing role of the humanist tradition, in such a way that the exemplarity of the histories emerges as a essential element for the configuration of an arte dello stato. This formulation of the commonplace in his work is linked to a critical approach to the imitation of ancient times and the examples collected in histories through a double articulation that places him in an eclectic position between classicism and novelty.
\end{abstract}

KEYWORDS: Machiavelli, historia magistra vitae, Koselleck, imitation, exemplarity, fortune, occasion.

Desde la Antigüedad hasta mediados del siglo XVIII, la fórmula ciceroniana historia magistra vitae ha sido considerada como un lugar común en aquellos escritos donde, de una manera más o menos explícita, se reflexiona sobre la naturaleza y utilidad de la historia. Más allá del uso retórico, la fórmula pone en juego, como ya señalara Reinhart Koselleck, un modo de concebir la relación entre el pasado y el futuro completamente distinta a la manera en que dicha relación será pensada con la aparición del concepto moderno de historia. Se trata, por tanto, del topos que refleja un concepto de historia que quedará disuelto en virtud de una nueva conceptualización a mediados del siglo XVIII. El nuevo paradigma, preparado durante decenios de manera difusa en distintos escritos, desdeñará 
el tiempo pasado y su ejemplaridad repetible, proyectándose hacia el futuro en tanto que tiempo histórico esencial ${ }^{1}$.

En este sentido, el presente trabajo pretende determinar de qué modo opera el mencionado topos en la obra de Nicolás Maquiavelo, considerando que de su utilización se deriva un modo de concebir la historia con una efectividad práctica irrenunciable para el autor florentino. Se trata, además, de abordar la historia como magistra vitae en el contexto del Renacimiento italiano, donde adquiere una fuerza renovada, en contraposición a la vigencia de la misma durante la Edad Media, y cuya presentación en la obra maquiaveliana se encuentra relacionada con reflexiones en torno a la problemática de la imitación. Nuestro objetivo será, por tanto, tratar de determinar la relación existente entre la concepción de la historia maquiaveliana y el problema de la imitación como su correlato. Así pues, el modo de concebir la relación entre pasado y futuro en la fórmula ciceroniana, considerando su prolongada durabilidad, lejos de ser subsumible a un principio unificador que permita explicar de manera inequívoca su significado, requiere de una consideración históricamente comprometida con los usos concretos del mismo en la obra de Nicolás Maquiavelo con el objeto de presentar la originalidad con la que dicho lugar común se presenta y evitar así caer en un substancialismo histórico en el estudio de los topoi.

Por otro lado, la temática aquí abordada queda justificada en la medida en que resulta necesaria una aclaración general sobre los usos y referentes del término "historia". La necesidad de tal aclaración se comprueba simplemente al observar la sistemática e inoportuna aplicación a la obra maquiaveliana de una noción de "historia" en sentido moderno, apreciable en algunas de las traducciones disponibles en castellano ${ }^{2}$ y en gran parte de la bibliografía secundaria. Se trata, entonces, de hacer visible la problemática que se oculta detrás de ciertas interpretaciones y traducciones que obstaculizan una comprensión, quizá más aproximada, sobre el uso del término "historia” y su concepto, con el objeto de evitar confundir la identidad de la palabra con la identidad del concepto, debida a la aplicación de un significado al pasado que el concepto de historia sólo adquiere a partir de la Modernidad.

${ }^{1}$ R. KOSELLECK, "Historia magistra vitae", Futuro pasado: Para una semántica de los tiempos históricos, Barcelona: Paidós, 1993, 41-66.

${ }^{2}$ Como excepciones a este respecto cabría señalar la Antología de Maquiavelo, al cuidado de Miguel Ángel Granada y la edición de los Discursos sobre la primera década de Tito Livio, de Roberto Raschella. 
En definitiva, pese a que la falta de sistematicidad en la obra maquiaveliana ha sido con frecuencia motivo de discusión sobre la relevancia de un estudio filosófico de su obra $^{3}$, consideramos que este carácter asistemático de sus planteamientos, que ha llevado a algunos a considerar la obra maquiaveliana subordinada a intereses estrictamente políticos, constituye una dificultad que no exime al intérprete contemporáneo de pensar, también desde el ámbito de la filosofía, las diversas problemáticas que se encuentran en la obra del célebre florentino ${ }^{4}$

\section{Historia como magistra vitae: sobre el carácter ejemplar de las historias}

La fórmula ciceroniana historia magistra vitae ${ }^{5}$ ha sido interpretada por Reinhart Koselleck ${ }^{6}$ como un lugar común en la concepción de la historia premoderna, cuya gradual disolución en el último tercio del siglo XVIII implicó la aparición de un nuevo concepto de historia (relacionado a su vez con la génesis de la filosofía de la historia ${ }^{7}$ ) carente de cualquier significado narrativo o ejemplar ${ }^{8}$.

El planteamiento de Koselleck en el marco de la Begriffsgeschichte, cuyo trabajo interdisciplinar queda reflejado en el monumental Geschichtliche Grundbegriffe? ${ }^{9}$, analiza los

\footnotetext{
${ }^{3}$ Cfr. M. GAILLE, Maquiavelo y la tradición filosófica, Buenos Aires: Nueva Visión, 2011.

4 "Una cosa es que se pretenda que Maquiavelo es un filósofo en el sentido más típico del término, esto es, un autor centrado básicamente en el análisis sistemático de las ideas propuestas por la tradición filosófica, o en este caso filosófico-política; en efecto, es muy posible que no sea ésta una buena manera de caracterizar a Maquiavelo. Pero otra cosa muy distinta es negar la voluntad de teorización de un autor que se esfuerza sistemáticamente en pensar ciertos fenómenos políticos e históricos que necesariamente incumben a la filosofía" (J. M. FORTE, "Estudio introductorio", en Maquiavelo, Madrid: Gredos, 2010, LXII).

${ }^{5}$ La enunciación más célebre del topos en Cicerón se encuentra en De oratore: "Historia vero testis temporum, lux veritatis, vita memoriae, magistra vitae, nuntia vetustatis". "La historia misma, testigo de los tiempos, luz de la verdad, vida de la memoria, maestra de la vida, mensajera de la antigüedad" (M. T. CICERÓN, De oratore, II, 9, 36, en Obras Completas de Marco Tulio Cicerón, vol. 1, [traducción M. Menéndez Pelayo], Buenos Aires: Anaconda, 1946).

${ }^{6}$ Sin embargo, está pendiente aún, según Koselleck, un estudio general sobre el topos: "Así, falta una historia de la fórmula historia magistra vitae, dado que lo que se quiere decir con ella al menos ha guiado durante los siglos la autocomprensión de los historiadores, cuando no su producción. A pesar de la identidad verbal, el valor de nuestra fórmula fluctuó considerablemente en el curso del tiempo" (R. KOSELLECK, Futuro pasado, 43).

7 Ibíd., 57.

8 Ibíd., 50.

${ }^{9}$ O. BRUNNER, W. CONZE, R. KOSELLECK (Hrsg.): Geschichtliche Grundbegriffe: Historisches Lexikon zur politisch-sozialen Sprache in Deutschland, 8 Bände in 9., Stuttgart: Klett-Cotta, 1972-1997. Para un estudio sobre la cuestión metodológica en la historia de los conceptos y su relación con la hermenéutica cfr. J. L. VILLACAÑAS; F. ONCINA, "Introducción", en R. KOSELLECK y H. G. GADAMER, Historia y hermenéutica, Barcelona: Paidós, 1997.
} 
cambios que sufre el uso del término "historia" desde su aparición hasta el surgimiento de la filosofía de la historia, en la medida en que dichas modificaciones ponen de relevancia un cambio en la relación entre pasado y futuro, y por ende, en la concepción del tiempo histórico. El término "historia", tal y como se entiende en la actualidad constituye, en palabras de Koselleck, casi un neologismo ${ }^{10}$. En este sentido, el uso actual de dicho término, que hunde sus raíces en el siglo XVIII, es el resultado de dos procesos a partir de los cuales el significado antiguo del mismo se ve notoriamente modificado:

El primero de los dos procesos consiste en la formación del colectivo singular que aglutina en un concepto común la suma de las historias individuales. El segundo, en la fusión de "historia" [Geschichte] como conexión de acontecimientos y de "Historia" [Historie] en el sentido de indagación histórica, ciencia o relato de la historia ${ }^{11}$.

El resultado de dichos procesos da lugar a la historia entendida como historia única que da sentido a todas las historias y a las acciones humanas, y que deja sin aplicación a la fórmula historia magistra vitae. El primer proceso, caracterizado como el surgimiento del colectivo singular Geschichte, obedece al cambio que se produce a partir del siglo XVIII, donde este término, anteriormente en forma plural y que significaba fundamentalmente "sucesos o acontecimientos", pasa a referirse en singular a "una serie de eventos en un todo coherente. La "historia" adquirió una significación que trascendía los hallazgos o los hechos individuales"12. De este modo, el hecho de que el significado narrativo o ejemplar perdiera su interés en aras del sentido general de la historia conlleva que el colectivo singular "historia" se convierta en la condición de posibilidad de las demás historias, de tal modo que se trata de una historia en general como instancia última.

En cuanto al segundo proceso como fusión de Historia (Historie) e historia (Geschichte), donde el término "historia" (Geschichte) recoge en sí el término "Historia"

\footnotetext{
${ }^{10}$ R. KOSELLECK, historia/Historia, Madrid: Trotta, 2010, 27. Sobre la particularidad del concepto moderno de historia: "De repente hemos hablado de la historia, de la "historia misma", en un singular de difícil significación sin un objeto ni un sujeto coordinados. Esta locución única completamente usual para nosotros procede también de la segunda mitad del siglo XVIII” (R. KOSELLECK, Futuro pasado, 53).

${ }^{11}$ R. KOSELLECK, historia/Historia, 27. Dicha problemática resulta comprensible únicamente a partir de la consideración de la particularidad de la lengua alemana en lo que refiere a los términos "Historie" y "Geschichte". A este respecto nuestra utilización de los mismos sigue las indicaciones de Antonio Gómez Ramos en la introducción a su edición del texto.

12 Ibíd., 29.
} 
(Historie), nos encontramos ante la unión de los tres sentidos en un sólo término, es decir, Geschichte pasará a referirse tanto a los eventos sucedidos, como a la narración de los mismos y a la ciencia de la historia: "Lo decisivo era que en el último tercio del siglo XVIII se traspasó un umbral. Los tres planos: estado de cosas, exposición y ciencia de ello se ponen ahora bajo un concepto común único como "historia"13.

Sin embargo, por contraposición al significado moderno del término "historia", el lugar común que ocupa la fórmula ciceroniana tiene como una de sus características definitorias el hecho de que su operatividad se encuentra condicionada por la admisión de una constancia en la naturaleza humana y una constancia de los hechos en tanto que similares ${ }^{14}$. Asimismo, esta aparición del concepto moderno de historia supone el rechazo de la noción de historia antigua que se encontraba siempre vinculada a los ciclos naturales ${ }^{15}$.

De este modo, la descripción de la disolución del topos desarrollada por Koselleck resulta clave para comprender las diferencias en las concepciones de la historia antigua y moderna, de modo que la concepción de la primera queda sustituida por la historia como conexión universal de sucesos. Por tanto, resulta imprescindible no confundir este uso de "historia" en sentido colectivo, con aquel que permitía llamar a la disciplina de la historia, esto es, la historiografía, en singular ${ }^{16}$, cuyo uso se encuentra con cierta, aunque reducida, frecuencia en la obra maquiaveliana.

\subsection{La formulación del topos en la obra maquiaveliana}

Partiendo de la reflexión sobre la disolución del topos ciceroniano, Koselleck señala que en Maquiavelo se halla una recuperación de la utilidad de la historia bajo la exigencia de

\footnotetext{
13 Ibíd., 45.

14 Ibíd., 44.

15“'Hasta el siglo XVIII, la prosecución y el cómputo de los sucesos históricos estaban garantizados por dos alegorías naturales del tiempo: el curso de los astros y el orden de sucesión de soberanos y dinastías. Pero Kant al desestimar toda interpretación de la historia desde datos astronómicos fijos y al señalar el principio de sucesión como contrario a la razón renuncia también a la cronología habitual como hilo conductor analítico" (R. KOSELLECK, Futuro pasado, 58-59).

${ }^{16}$ En este sentido, es necesario atender a la diferencia entre el uso singular de "historia" en su sentido moderno, con el uso singular del mismo término en referencia a la historiografía: "La "Historia", como doctrina o disciplina científica, ya había podido aplicarse siempre de modo reflexivo y sin referirse a un objeto. Desde Cicerón toda la ciencia de las historias individuales había quedado subsumida bajo el término "Historia": historia magistra vitae" (R. KOSELLECK, historia/Historia, 42).
} 
tomar a los antiguos como modelos ${ }^{17}$, afirmación que se apoya exclusivamente en la cita al proemio del libro primero de Discursos sobre la primera década de Tito Livio. Ciertamente Koselleck no pretende en ese texto realizar un estudio sobre la vigencia de la fórmula sino, precisamente, sobre las causas de su disolución y, en este sentido, las distintas menciones sobre su durabilidad ejercen un papel testimonial sobre algo que caerá en el olvido con la aparición del concepto moderno de historia. Mas precisamente por ello resulta imprescindible matizar esta afirmación mediante la referencia a otros textos donde Maquiavelo aborde, incluso con mayor detalle, la problemática de la fórmula ciceroniana.

La formulación más aproximada del topos ciceroniano en la obra de Maquiavelo se encuentra en un texto de 1503, donde el autor introduce, mediante estilo indirecto, el papel de las historias como maestras de nuestras acciones:

Yo he oído decir que las historias son las maestras de nuestras acciones y especialmente de los príncipes, y que el mundo estuvo siempre de la misma manera habitado por hombres que han tenido siempre las mismas pasiones y que siempre hubo quien obedece y quien manda, quien obedece de mala gana y quien obedece de buena gana, quien se rebela y es castigado ${ }^{18}$.

De este modo, la enunciación de la fórmula se encuentra mediada por la utilización en plural del término, de manera que, remitiendo a una pluralidad, las historias se presentan como útiles para los príncipes y, en general, para la actividad política. La utilización por parte de Maquiavelo del término "historia", cuando se relaciona con su utilidad, se encuentra en la mayoría de los casos en número plural, lo cual resulta especialmente relevante cuando se compara con la generalización del uso en singular de dicho término desde del siglo XVIII en un sentido muy específico. De este modo, resulta necesario subrayar que cuando Maquiavelo utiliza, en pocas ocasiones, en singular el término "historia" se refiere a la narración concreta de un determinado autor, por ejemplo, la historia de Tito Livio; o bien, a la historia como disciplina. Por lo tanto, desestimando el

17 "Con la sublimación de las esperanzas sobre los últimos tiempos volvió a abrirse paso la historia antigua como maestra. Con la exigencia de Maquiavelo, no sólo de admirar a los mayores, sino también de tomarlos como modelo, confirió su actualidad a la intención de conseguir continuas utilidades para la Historie, porque había unido el pensamiento ejemplar y el empírico en una nueva unidad" (R. KOSELLECK, Futuro pasado, 45). 
hecho que se trate de una simple "moda"19 de la época, se trata de ahondar en la cuestión de qué significado de "historia" se encuentra en ese uso en plural del término.

Asimismo, este escrito temprano pone en juego una relación especialmente relevante para el trabajo que aquí nos ocupa, esto es, la relación entre las historias como maestras de nuestras acciones y la imitación de los antiguos. Maquiavelo señala, por un lado, las condiciones necesarias para su aceptación; y por otro, la necesidad de la imitación de los antiguos, siempre que se entienda de manera correcta el hecho de que las historias son las maestras de nuestras acciones, para lo que resulta imprescindible una remisión a los hechos contemporáneos, lo que permite comparar su similitud con lo acontecido con los pueblos latinos:

Si alguien no lo cree, que mire en Arezzo el año pasado y en todos los territorios de Valdichiana, que hacen algo muy similar a lo de los pueblos latinos. Tanto en uno como en otro caso se ve la rebelión y luego la reconquista; aunque en la forma de la rebelión y de la reconquista haya bastante diferencia, sin embargo, la rebelión y la reconquista es similar. Por lo tanto, si es cierto que las historias son las maestras de nuestras acciones, no estaba mal que quien tenía que castigar y juzgar los territorios de Valdichiana tomara ejemplo e imitara a quienes fueron los señores del mundo, especialmente en un caso que ellos os enseñan con exactitud cómo os tenéis que gobernar ${ }^{20}$

A continuación, pese al estilo indirecto utilizado en la primera formulación del topos y a la segunda enunciación presentada en el mismo texto de manera condicional, Maquiavelo afirma su valor mediante el análisis de la situación contemporánea de Valdichiana que merece ser censurada en comparación con lo ocurrido con los antiguos pueblos latinos, siendo la decisión de los romanos digna de ser alabada.

\footnotetext{
${ }^{18}$ N. MAQUIAVELO, "Cómo tratar a los pueblos rebeldes de Valdichiana", Antología de Maquiavelo, Barcelona: Península, 2009, 193.

${ }^{19}$ Como muestra sobre la frecuente ausencia de reflexión sobre esta temática cabe señalar las palabras del traductor de las Historias florentinas: "En cuanto al título en plural de Istorie fiorentine, Maquiavelo no hizo más que seguir una moda ya difundida entre los humanistas italianos del siglo XV y seguida también por algunos historiadores del siglo XVI" (F. FERNÁNDEZ MURGA, "Introducción", Historia de Florencia, Madrid: Tecnos, 2009, XXXIX).

${ }^{20}$ N. MAQUIAVELO, "Cómo tratar a los pueblos rebeldes de Valdichiana”, Antología de Maquiavelo, 193194.
} 
Así pues, esta utilización en plural del término "historia" conecta la idea de las historias como maestras de vida con las nociones de lezione delle cose antique ${ }^{21}$ y lezione delle cose del mondo ${ }^{22}$ que hallamos en sus dos obras principales. La relación entre estas nociones es abordada, por un lado, en la dedicatoria de El príncipe, como combinación entre la experiencia de las cosas modernas y la lectura de las antiguas, que da lugar al conocimiento de las acciones de los grandes hombres; y por otro, en la dedicatoria de los Discursos, como resultado de una larga práctica y lectura de las cosas del mundo. Así pues, el término lez̧ione, que significa primariamente la acción de leer -esto es, lectura- pero que podría entenderse también como lección en el sentido de enseñanza, se encuentra relacionado con las historias narradas como fuentes de conocimiento, cuyo valor constituye, junto a la experiencia, un papel fundamental en la redacción de la obra de Maquiavelo 23 .

Asimismo, es necesario señalar la importancia que tiene la temática de la utilidad de las historias para Maquiavelo en el contexto de los Discursos, en la medida en que el tratamiento de la misma es presentado como un novedoso procedimiento:

Sin embargo, empujado por ese natural deseo que siempre ha existido en mí de obrar sin temor alguno en aquellas cosas que creo acarrean común beneficio para todos, he decidido tomar un camino que, por no haber sido recorrido todavía por nadie ${ }^{24}$, si me

${ }^{21}$ N. MAQUIAVELO, El príncipe, dedicatoria, Madrid: Biblioteca Nueva, 2004, 69.

${ }^{22}$ N. MAQUIAVELO, Discursos sobre la primera década de Tito Livio, Dedicatoria, traducción de R. Raschella, Buenos Aires: Losada, 47.

${ }^{23}$ A este respecto se encuentra en la famosa carta de Maquiavelo a Vettori una explicitación de la relación entre las enseñanzas derivadas de la lectura de los antiguos y la escritura de El príncipe: "Y en el umbral me despojo de mis vestidos cotidianos, llenos de fango y lodo, y me visto de ropas nobles y curiales. Entonces, dignamente ataviado, entro en las cortes de los hombres antiguos, donde, amablemente recibido por ellos, me deleito con ese alimento que es sólo para mí, y para el que yo nací. Y no me avergüenzo de hablar con ellos, y de preguntarles por las razones de sus acciones. Y ellos por su humanidad me responden [...]Y como Dante dice que no hay saber si no se guarda lo que se ha comprendido yo he anotado lo que he sacado con su conversación, y he compuesto un opúsculo, De principatibus, en el que profundizo cuanto puedo en las dificultades de esta materia " (N. MAQUIAVELO, Epistolario privado, 40, N. Maquiavelo a F. Vettori, 10 de diciembre de 1513, edición y traducción de J. M. Forte, Madrid: Esfera de los libros, 2007, 209).

${ }^{24} \mathrm{~F}$. Bausi en la edición crítica de los Discursos señala que esta expresión remite al topos formulado, entre otros, por Cicerón en De oratore, 3, II "Inusitatas vias indagemus, tritas relinquamus" "abrimos inusitadas vías y dejamos las comunes y trilladas". Citado por Bausi en Discorsi sopra la prima deca di Tito Livio, ed. F. Bausi, Edizione Nazionale delle Opere, 2 tomi, Roma: Salerno, 2001, 3. A nuestro juicio, su afirmación no se reduce a la mera reproducción de un lugar común, sino que hace referencia a la efectiva concepción de su propio planteamiento como algo nuevo en la época y que se encuentra ligado al problema de la imitación. 
puede provocar fastidios y dificultades, también puede darme el premio de quienes consideren humanamente la finalidad de estos mis trabajos ${ }^{25}$.

A continuación, Maquiavelo señala que dicha novedad está relacionada con un error ${ }^{26}$, esto es, el hecho de que en su tiempo el honor atribuido a los tiempos antiguos haya sido promovido en variados campos mediante la imitación, mientras que "no hay príncipe ni república que recurra a los ejemplos de los antiguos" 27 . Se presenta, por tanto, el conocimiento de las acciones de los antiguos y la necesidad de imitarlos en política, pero señalando como un error que impide esta asociación la carencia de un verdadero conocimiento de las historias:

Y creo que ello no se debe tanto a la debilidad a que la actual educación ha llevado al mundo, o a ese mal que un ambicioso ocio ha hecho a muchas provincias y ciudades cristianas, cuanto al hecho de no tener verdadero conocimiento de las historias, por no saber extraer de ellas al leerlas ese sentido, ni gustar de ellas ese sabor que tienen en sí mismas. De donde nace que infinitas personas que las leen, experimentan el placer de oír esa variedad de sucesos que ellas contienen, sin pensar para nada en imitarlas, juzgando que la imitación no sólo es difícil sino imposible, como si el cielo, el sol, los elementos, los hombres, hubieran variado de movimiento, de orden y de potencia respecto de lo que eran antiguamente ${ }^{28}$.

Así pues, la ausencia de un verdadero conocimiento de las historias impide extender la imitación a la política, porque éstas sólo son leídas por mero deleite y admiración, pero dado que no se trata de leer las historias por la mera admiración de los antiguos, se ha de entender la utilidad de las mismas como modelos políticos ejemplares ${ }^{29}$. Es precisamente

\footnotetext{
${ }^{25}$ N. MAQUIAVELO: Discursos, I, proemio, Buenos Aires: Losada, 49. Más allá del debate sobre si este texto forma o no parte de la redacción definitiva, en la medida en que habría sido corregido por Maquiavelo, puesto que los dos primeros párrafos del proemio se encuentran ausentes en algunos de los manuscritos, pero es posible encontrarlos en el único fragmento autógrafo de Maquiavelo, consideramos su inclusión por la estrecha relación que éste establece entre historias e imitación.

${ }^{26}$ Ibíd., 51.

${ }^{27}$ Ibíd., 50.

${ }^{28}$ Ibíd., 50-51.

${ }^{29}$ En este sentido, Maquiavelo señala también en El arte de la guerra la utilidad política de atender a los hechos pretéritos como ejemplos: "Alejandro, César y todos los grandes hombres y famosos príncipes de pasados tiempos, combatían en las primeras filas, caminaban armados a pie y, si perdían sus Estados, era perdiendo también la vida, viviendo y muriendo dignamente. Podrá censurarse en todos o en algunos de ellos sobrada ambición de dominar, pero no que se entregaran a la molicie ni a cosa alguna de las que
} 
en este contexto donde el hecho de traducir al español en singular "la historia", tal y como se observa en algunas traducciones ${ }^{30}$ puede dar lugar a entender la historia considerada como compendio de los acontecimientos reunidos bajo un sentido unitario. Sin embargo, ese sentido (quel senso) y ese sabor (quel sapore) a los que se refiere Maquiavelo, lejos de remitir a un sentido unitario dentro de la historia, tienen a nuestro juicio una función anafórica dentro del texto, esto es, consisten en el sentido político antes mencionado, que no se busca en las historias y que se encuentra completamente ausente en la época contemporánea, tal y como había señalado con anterioridad.

En definitiva, Maquiavelo no apela en absoluto a la historia de los hechos sin estar mediada por la narración de los mismos, esto es, en Maquiavelo no hay una historia por encima de las historias. Por otro lado, la traducción al español en singular supone anular la pluralidad a la que Maquiavelo se refiere, esto es, la diversidad de historias narradas que constituyen las fuentes de la obra maquiaveliana, rigurosamente estudiadas entre otros por G. Inglese ${ }^{31}$, en tanto que las mismas no se reducen a la historia de Tito Livio, sino que incluyen las historias de autores tan diversos como Diodoro, Herodiano, Plutarco, Polibio, Tucídides, Jenofonte, Salustio o Tácito.

\section{3 La crítica sobre el valor de las historias y el doble cariz de la ejemplaridad}

En el proemio al libro segundo de los Discursos, Maquiavelo matiza su postura inicial sobre el valor de "las cosas antiguas", presentando la admiración de los tiempos antiguos como una posible fuente de error, de tal modo que se encuentra en este texto una reflexión sobre la naturaleza de las historias como fuentes de información. La primera de las causas $^{32}$ del error en alabar a los antiguos plantea una duda sobre la labor de los

enervan y degradan a los hombres. Si nuestros principes leyeran y creyeran estas cosas, seguramente cambiarian de vida, y sus Estados, de fortuna" (N. MAQUIAVELO, El arte de la guerra, en Maquiavelo, Madrid: Gredos, 2010, 243). ${ }^{30}$ Sobre la omisión de esta problemática en el pasaje citado de los Discursos bastan como referencias las siguientes traducciones: "como de no tener perfecto conocimiento de la historia o de no comprender al leerla, su verdadero sentido ni el espíritu de sus enseñanzas" (Discursos sobre la primera década de Tito Livio, traducción de Luis Navarro, en Maquiavelo, Madrid: Gredos, 2010); y "como de no tener verdadero conocimiento de la historia, y de no extraer, al leerla, su sentido, ni gozar del sabor que encierra" (Discursos sobre la primera década de Tito Livio, introducción, traducción y notas de Ana Martínez Arancón, Madrid: Alianza, 2000).

${ }^{31}$ Cfr. G. INGLESE, Per Machiavelli: l'arte dello stato, la vera cognizione delle storie, Roma: Carocci, 2006.

32 Por lo que respecta al segundo motivo para no aceptar de manera irreflexiva la alabanza de los tiempos antiguos éste se encuentra relacionado con el hecho de que el odio nace del temor y la envidia, y esto no 
historiadores ${ }^{33}$. Así pues, según Maquiavelo, en ocasiones no se conoce la verdad porque se trata de unos hechos narrados por historiadores que se dejan llevar por la fortuna de los vencedores, de modo que de esta observación se desprende una crítica sobre la recepción de las historias, que modifica, no sólo el tipo de enseñanza que pueda llegar a derivarse de las historias, sino también una cierta corrección a la noción de imitación de los antiguos, señalada en el proemio al libro primero, en un sentido que más adelante retomaremos.

Nos encontramos, por tanto, con una crítica a la noción de autoridad en la obra maquiaveliana, en la medida en que se considera que los historiadores no siempre narran con veracidad las cosas antiguas. Así pues, es necesario tener en cuenta también que la afirmación del topos no supone la aceptación de las historias como autoridades ${ }^{34}$, por el contrario, una afirmación contraria a la razón, aunque fuera autorizada por los más excelentes historiadores, carecería de interés. De este modo, los ejemplos que son contrarios a los argumentos no tienen valor, tampoco la autoridad de Tito Livio, como en el caso en el que Maquiavelo, contra éste y otros historiadores, afirma que la multitud es más sabia y constante que un príncipe:

No sé si me meteré en una provincia dura y tan llena de dificultades que me obligará a abandonarla con vergüenza o perseverar en ella, queriendo defender una causa a la que, como he dicho, todos los escritores acusan. Pero, como sea, no juzgo ni juzgaré jamás

puede darse respecto a los tiempos de los antiguos, en primera instancia por un argumento psicológico pero también objetivo y es que las historias no recogen los detalles más desagradables mientras que los de la actualidad son por todos conocidos.

${ }^{33}$ N. MAQUIAVELO, Discursos, II, proemio, 205. Sobre esta misma temática Maquiavelo señala la influencia negativa de César sobre la libertad de los escritores: "Y que nadie se engañe por la gloria de César, al oír cómo lo celebran, especialmente los escritores, porque quienes lo elogian están corrompidos por su fortuna y atemorizados por la grandeza del imperio. Porque César, amparándose bajo su nombre, no permitía que los escritores hablaran libremente de él. Pero, si alguien quiere saber qué decían los escritores libres, debe ver cuanto dicen de Catilina" (N. MAQUIAVELO, Discursos, I, 10, 85).

${ }^{34} \mathrm{~A}$ este respecto ha sido $\mathrm{F}$. Bausi quien ha insistido en subrayar las diversas dificultades que supone la cuestión de los modelos y las fuentes en Maquiavelo, en la medida en que tanto la lectura de los antiguos como el valor de sus ejemplos se encuentran mediados por la interpretación que de ellos extrae Maquiavelo, llegando en ocasiones a tergiversar el sentido de los textos originales o a incluir palabras ausentes en los textos citados. A partir de estas comprobaciones, estaríamos ante la cultura no de un erudito, sino de quien se sirve de los libros para dar cuerpo a sus ideas y adquirir un repertorio de ejemplos para fines persuasivos, más relacionados con la capacidad literaria que con la verdad histórica. Cfr. F. BAUSI, "Modelli e fonti. La cultura di Machiavelli”, Machiavelli, Roma: Salerno, 2005, 181-193. 
que sea un defecto defender cierta opinión con las razones, sin querer usar la autoridad o la fuerza ${ }^{35}$

Así pues, Maquiavelo se distancia de una postura ingenua sobre el valor de las historias, lo cual no obsta, por otro lado, a que reconozca en los tiempos antiguos una virtud mayor que la propia de sus tiempos, mediante el recurso a la metáfora del sol ${ }^{36}$, en la medida en que se trata de una recepción crítica del valor de las mismas, puesto que su aceptación se encuentra mediada por un análisis de cada situación concreta:

No sé entonces si yo mereceré ser incluido entre los que se engañan, si en estos mis discursos elogio demasiado los tiempos de los antiguos Romanos y censuro los nuestros. Y realmente, si la virtud que entonces reinaba y el vicio que ahora reina no fueran más claros que el sol, mi palabra sería más contenida, dudando de no incurrir en este engaño del que acuso a algunos. Pero, siendo la cosa tan manifiesta que cualquiera la ve, me animaré a decir manifiestamente lo que comprendo de aquellos tiempos y de estos tiempos ${ }^{37}$.

Asimismo, siguiendo en la línea de reflexión crítica del conocimiento proporcionado por las historias, Maquiavelo contempla en distintos pasajes el hecho de que se haga una lectura juiciosa de las historias ${ }^{38}$, de modo que, en repetidas ocasiones, Maquiavelo, en vez

\footnotetext{
${ }^{35}$ N. MAQUIAVELO, Discursos, I, 58, 191. Sobre otra crítica contra la noción de autoridad como fuente de legitimación de su discurso es patente el paralelismo con una carta a Vettori, donde Maquiavelo se pronuncia sobre Fernando de Aragón: "Y cuando se ve a un grande cometer un error así, se puede presumir que comete mil; ni creo que debajo de esta decisión de ahora pueda haber algo más de lo que se ve, porque yo no bebo nombres, ni quiero que en estas cosas me mueva autoridad alguna sin usar la razón. Por tanto, concluyo que, si son ciertos vuestros razonamientos, pudo haberse equivocado, y que razonó mal y resolvió peor" (N. MAQUIAVELO, Epistolario privado, 28, Maquiavelo a F. Vettori, 29 de abril de 1513, Madrid: Esfera de los Libros, 2007, 149).

${ }^{36} \mathrm{La}$ metáfora de la luz, frecuentemente utilizada por Maquiavelo, ha sido estudiada por Blumenberg como metáfora de la verdad que recorre todo el pensamiento occidental: "Das Licht als Metapher der Wahrheit. Im Vorfeld der philosophischen Begriffsbildung", Ästhetische und metaphorologische Schriften, Frankfurt am Main: Suhrkamp, 2001, 139-171.

${ }^{37}$ N. MAQUIAVELO, Discursos, II, proemio, 208.

${ }^{38}$ En este sentido, son varios los pasajes donde Maquiavelo apela a una lectura atenta: "Y quien lea sensatamente todas las historias [...]" ( Discursos, I, 23, 119); "El que lea la Biblia sensatamente, verá que Moisés, si quería que sus leyes y sus órdenes se cumplieran, se vio forzado a matar a infinitos hombres que, movidos solamente por la envidia, se oponían sus proyectos"(Discursos, III, 30, 412); "De modo que, a quien examine con diligencia las cosas pasadas [...] pero, como estas consideraciones son descuidadas o no comprendidas por los lectores [...]" (Discursos, I, 39, 151).
} 
de referirse sin más a la necesidad de leer las historias, matiza la necesidad de leerlas "sensatamente".

De este modo, la crítica de Maquiavelo contra la lectura de las historias por el mero deleite y el aumento de la erudición se encuentra relacionada con la necesidad de adoptar una postura crítica sobre la imitación de los ejemplos antiguos, pues su verdadero conocimiento se entiende como una vía práctica efectiva de cara a la confección de un saber político útil. Así pues, la utilidad de las historias nos remite a un conocimiento mediante ejemplos ${ }^{39}$ de tal modo que se halla en los textos una constante remisión a los hechos pretéritos por ofrecer ejemplos útiles para la vida política ${ }^{40}$. Sin embargo, este carácter ejemplar de las historias no se refiere únicamente a ejemplos positivos cuyo modelo se ha de seguir, como paradigmáticamente se observa en el caso de la república romana, sino que las historias pueden enseñar también por la vía negativa:

Nada fue más difícil para los Romanos que superar a los pueblos de sus entornos y a parte de las provincias lejanas, por el amor que en aquellos tiempos muchos pueblos tenían por la libertad [...] Porque muchos ejemplos nos hacen conocer los peligros que corrían para mantener o recuperar esa libertad, y las venganzas que tomaban contra quienes se las quitaban. Se conoce también ahora en la lección de las historias los daños que los pueblos y las ciudades reciben por la servidumbre ${ }^{41}$.

Esta idea de los contramodelos recogidos en las historias aparece tematizada de manera explícita en las Historias de Florencia, pues tan útil resulta conocer las glorias antiguas como hacer ver las causas de la corrupción para evitarlas o corregirlas:

[...] porque si hay algo que deleita y agrada en la historia es precisamente lo que se describe detalladamente; y si alguna lección resulta útil a los ciudadanos que gobiernan las

\footnotetext{
${ }^{39}$ N.MAQUIAVELO, Discursos, I, 3, 62.

40 "Es imposible que quienes viven privadamente en una república, o los que, por la fortuna o por la virtud, se han convertido en príncipes, si leyeran las historias e hicieran acopio de las memorias de las cosas antiguas, no quisieran, los privados vivir en su patria como los Escipiones y no como los Césares, y quienes son príncipes, más bien como los Agesilaos, los Timoleones y los Diones, y no como los Nabis, Falaris y Dionisios"N. MAQUIAVELO, Discursos, I, 10, 84-85).

${ }^{41}$ N. MAQUIAVELO, Discursos, II, 2, 213.
} 
repúblicas es la que expone los motivos de los odios y las rencillas de una ciudad, a fin de que, escarmentados en el mal ajeno, puedan dichos ciudadanos mantenerse unidos ${ }^{42}$.

Por lo tanto, la ejemplaridad de las historias no se reduce sin más a los antiguos romanos como modelos sino que, como señala Cabrini, hay "una vertiente negativa de la ejemplaridad" en las Historias florentinas, es decir, se trata de una doble articulación de la utilidad de las historias donde hay cabida para las mismas como antimodelos que narran las causas de la decadencia ${ }^{43}$. Nos encontramos, por tanto, ante un doble cariz de la ejemplaridad en las historias, pues su valor no se reduce a la afirmación de modelos a imitar sino que tiene como punto no menos relevante la presentación de ejemplos a evitar.

De este modo, queda puesto de manifiesto que el lugar de las historias como magistra vitae en la obra maquiaveliana remite a un uso crítico, de modo que se recurre a las narraciones de los hechos pasados donde se ponen en juego ejemplos útiles para la vida política, tanto en sentido negativo como positivo.

\section{Entre clasicismo y novedad: el problema de la imitación}

El problema de la imitación en la obra de Maquiavelo, asociado como hemos señalado al conocimiento de las historias, tiene como punto central la imitación de los antiguos, cuya originalidad respecto al tratamiento de la misma que realizan otros autores de la época ha sido con frecuencia desatendida. Se trata, por ende, de presentar el problema de la imitación en la obra maquiaveliana en la medida en que éste no se deja explicar a partir de las coordenadas que han sido trazadas con anterioridad en la época, esto es, que no refiriéndose al campo de lo ontológico, lo estético o lo retórico, se presenta con una

\footnotetext{
${ }^{42}$ N. MAQUIAVELO, Historia de Florencia, proemio, Madrid: Tecnos, 2009, 24. En un sentido similar se pronuncia en el libro V: "Si las empresas de nuestros príncipes, dentro y fuera de nuestras fronteras, no despertarán quizás en los lectores admiración por su virtù y grandeza, como la de nuestros antepasados, acaso la despierten no menor por otras causas, al ver cómo, con ejércitos tan débiles y tan mal dirigidos, se logró frenar el poderío de tan ilustres pueblos. Y si al describir los hechos ocurridos en este mísero mundo no podrá hablarse de fortaleza en los soldados, ni de la virtù en los capitanes, ni de amor patrio en los ciudadanos, podrá verse en cambio de qué astucias y artimañas se sirvieron tanto los príncipes como los soldados y los jefes de las repúblicas para conservar el prestigio que no se habían merecido. Conocer todo esto quizás sea no menos útil que conocer las glorias antiguas, pues si éstas estimulan a los hombres generosos para que las imiten, lo otro los estimulará a evitarlo y corregirlo" (N. MAQUIAVELO, Historia de Florencia, V, I, 238-239).
} 
dimensión política y crítica desconocida para el humanismo, en la medida en que se halla relacionado constantemente con la experiencia de las cosas modernas.

Ha sido E. Cutinelli ${ }^{44}$ quien se ha ocupado de manera detallada del problema de la imitación en Maquiavelo. Su tesis principal sostiene que el clasicismo en Maquiavelo no es un proceso sin historia, sino que tiene un desarrollo inesperado e incluso dramático. Se trata, según Cutinelli, de una ruptura motivada por la polémica anticristiana que Maquiavelo presenta en los primeros cinco capítulos del libro $\mathrm{II}^{45}$, de modo que con ella se establece una cesura en la obra maquiaveliana a partir de esta crisis, donde la confianza en la posibilidad de realizar en el presente la lección de los antiguos, siendo Roma su modelo efectivo, se convierte en la consideración del modelo romano como criterio de condena a los tiempos presentes.

Sin embargo, nos parece que dicha lectura desatiende algunos pasajes ${ }^{46}$ que expresan una cierta continuidad en la temática de la imitación en Maquiavelo, consistente en una defensa de la misma atravesada por la crítica desde su presentación inicial. Es decir, la imitación no es abordada por Maquiavelo como algo susceptible de ser llevado a cabo de un modo ingenuo, tal y como parece leer Cutinelli en algunos pasajes ${ }^{47}$, sino que para Maquiavelo es precisamente en el análisis de las condiciones actuales como se observaría la utilidad de los ejemplos de los antiguos. En este sentido, el valor de las historias y la imitación de los ejemplos no son analizadas independientemente de las condiciones contemporáneas, sino que éstas resultan la medida desde la que se juzga su

\footnotetext{
${ }^{43}$ CABRINI. A. M., "La storia da non imitare: il versante negativo dell'esemplarità nelle Istorie Fiorentine" en Cultura e Scrittura di Machiavelli, Atti del Convegno di Firenze-Pisa, Roma: Salerno, 200.

${ }^{44}$ E. CUTINELLI, "Mito dell'antico e percezione del moderno in Machiavelli", en Versants, 2000, n 38, 139-152.

${ }^{45}$ Ibíd., 151.

${ }^{46}$ Por ejemplo, la relación existente entre los pasajes de los Discursos, I, proemio y III, 27 donde Maquiavelo afirma que el desconocimiento de las historias y la educación (o religión, según el manuscrito) son las causas por las que no se ha aplicado la imitación en política.

47 "Quería decir ganar un horizonte en el cual la imitación de lo antiguo dejase de ser estética y hedonística, y se hiciese, como había sido programáticamente indicado en la apertura de la obra, auténtica e integral. Imitar a los antiguos no era saber copiar una bella estatua: quería decir hacerse realmente antiguo, y hacer política como la hicieron los antiguos" (la cursiva es nuestra) (Ibíd., 147-148). Consideramos, pues, que Cutinelli toma como punto de partida una lectura radical de lo que Maquiavelo entiende por imitación en los pasajes anteriores a la presunta crisis de la teoría de la imitación en el segundo libro, lo cual es, por otro lado, la condición para poder hablar de crisis en el segundo libro. Es decir, si se presenta la imitación al principio con tal pretensión de autenticidad e integridad, es fácil encontrar dificultades a semejante postura en el segundo libro, donde nosotros entendemos por el contrario que Maquiavelo explicita las dificultades que él mismo menciona ya en el proemio al libro primero.
} 
utilidad. Esta idea es recogida por G. Weise, citado por el propio Cutinelli ${ }^{48}$. Asimismo, cuando Cutinelli presenta su análisis de los elementos principales de la polémica anticristiana en Maquiavelo como el motivo de crisis en "la teoría de la imitación" 49 (Discursos II, 2 y II, 5), su interpretación sobre dicha polémica en relación con el problema de la imitación resulta discutible. En este célebre pasaje que pone de relevancia su postura anticristiana, Maquiavelo afirma, con no poca sutileza, la eternidad del mundo mediante la impugnación del argumento en contra de la misma ${ }^{50}$. Con esta afirmación, Maquiavelo pone en duda la cosmología basada en la creatio ex nibilo, para lo cual se sirve de las periódicas destrucciones que afectan al mundo, llevando a cabo una naturalización de la religión cristiana ${ }^{51}$. Sin embargo, Cutinelli parece no tomar en consideración varias cuestiones fundamentales en este pasaje al señalar que:

Volviendo a razonar sobre el cristianismo en la nueva y distinta perspectiva del quinto capítulo, la religión de los modernos, a la par que la de los antiguos, se llegaba a encontrar inserta en una estructura cósmica que, siempre idéntica a sí misma, reparte el variar de las sectas y determina su duración. En esta situación, la relación entre las religiones de los antiguos y la religión de los modernos se presenta en términos de sustancial identidad. Por tanto, en la perspectiva del quinto capítulo la imitación deviene problemática, si no imposible, por otra razón, porque pensada en este cuadro, no solo las religiones son estructural y sustancialmente idénticas, sino que adquieren cada una en su ámbito, una propia e insuperable necesidad en la cual la imitación de la otra de sí es pura contradicción en términos [...] Maquiavelo había demostrado ser consciente de que en la explicación de la afirmación del cristianismo estaba en cuestión la posibilidad de la imitación de Roma. Había, por tanto, recorrido dos direcciones diametralmente opuestas: el cristianismo como radical diversidad de lo antiguo, y por eso como esencia de lo moderno y de su carencia; y el cristianismo como secta entre las sectas, que nace, vive y muere como toda

\footnotetext{
${ }^{48}$ G. WEISE, Il Rinascimento e la sua eredità, Napoli: Liguori, 1969, 104. Citado por E. Cutinelli, "Mito dell'antico e percezione del moderno in Machiavelli", 143.

49 "Lo que en todo caso era resquebrajado era la propia teoría de la imitación, centro de todo el proyecto teórico y práctico de la obra maquiaveliana [...] Maquiavelo había llegado a excavar el abismo entre lo antiguo y lo moderno, y por tanto, a hacer la imitación, precisamente en razón del abismo creado por la diferencia de religión, imposible" (E. CUTINELLI, Ibíd., 149).

${ }^{50}$ N. MAQUIAVELO, Discursos, II, 5, en Maquiavelo, Gredos: Madrid, 2010, 425-426.

51 J. M. FORTE, "Eternidad y Ciclo. La historia natural maquiaveliana Adversus Fideles", en Q. RACIONERO; S. ROYO (eds.), El fin de la filosofía de la historia, Madrid: Dykinson, 2005, 367.
} 
otra secta. No obstante, ambas direcciones se mostraban como incapaces de encontrar un punto arquimédico a partir del cual la posibilidad de la imitación se fundase críticamente ${ }^{52}$

En esta lectura existen al menos dos puntos problemáticos en la medida en que obvia, en primer lugar, el análisis realizado por Maquiavelo en el capítulo anterior ${ }^{53}$, que cifra la ignorancia como causa de la ausencia de imitación, y que no parece poder dar como resultado una crisis insuperable por el variar de las sectas, sino más bien una dificultad debida a la ignorancia.

A esta primera, se le añade el hecho de que Cutinelli interprete que las religiones como cuerpos naturales con su propio e inevitable ciclo hacen imposible la imitación. Pues Maquiavelo afirma, ciertamente, la diversidad de las religiones, pero es precisamente en virtud de la debilidad del cristianismo (que no fue capaz de imponer una nueva lengua y acabar con todas las noticias de Roma ${ }^{54}$ ), a partir de lo cual tiene sentido comparar ambas épocas y plantear, haciéndose cargo críticamente de la dificultad que ello supone, la posibilidad de la imitación.

Así pues, consideramos que la tesis de la eternidad del mundo, tal y como es presentada en el libro $\mathrm{V}$, constituye en el problema de la imitación no una crisis insuperable por la que la imitación carece de sentido o resulta contradictoria, sino más bien su presupuesto, que obviamente limita a la misma, pero en la que encuentra su apoyo. Esto es, en la medida en que Maquiavelo habla de la debilidad de la religión cristiana por no haber acabado con las noticias de las cosas hechas por los hombres excelentes, esto constituye la base material necesaria, mas no suficiente, para la imitación de los antiguos, porque sin las noticias del mundo antiguo no cabría en modo alguno la

\footnotetext{
52 E. CUTINELLI, "Mito dell'antico e percezione del moderno in Machiavelli", 149-150.

53 "Y como se dirá al final de esta materia, tantos ordenamientos observados por Roma, sea los pertinentes a las cosas internas como a las externas, en nuestros tiempos no son imitados, y tampoco se los ha tenido en cuenta para nada, juzgándolos algunos falsos, otros imposibles y otros más inapropiados e inútiles. Tanto que, quedándonos con esta ignorancia somos presa de todo el que ha querido pasearse por esta provincia” (N. MAQUIAVELO, Discursos, II, 4, 225).

54 "Se conoce esto examinando los procedimientos de la religión cristiana contra la pagana, pues destruyó todas sus instituciones y todas sus ceremonias, sin dejar memoria de esta antigua teología. Verdad es que no pudo borrar por completo las noticias de los hechos que ejecutaron hombres ilustres del paganismo, pero esto se debe a la necesidad de conservar la lengua latina, puesto que en ella escribía la nueva ley: de poderla promulgar en nuevo idioma, teniendo en cuenta las otras persecuciones que sufrió el paganismo, no quedaría memoria de los antiguos sucesos" (N. MAQUIAVELO, Discursos, II, 2, en Maquiavelo, Madrid: Gredos, 426). Se ha perdido, por tanto, la memoria de la antigua teología pero no la memoria de los hechos de los tiempos antiguos.
} 
posibilidad de imitación. Es más, llevando la tesis de Cutinelli a su extremo se acabaría con la condición misma que permite a Maquiavelo relacionar las cosas antiguas con su tiempo; y esta clase de error, al considerar la imposibilidad de la imitación (el cambio de todos los órdenes respecto de los tiempos antiguos), es advertido por el propio Maquiavelo desde el principio.

En todo caso, la tesis de Cutinelli tiene la virtud de incidir en la polémica anticristiana en relación con la cuestión de la imitación, en la medida en que Maquiavelo se refiere en varias ocasiones a la debilidad de la educación, agravante para el desconocimiento de las historias, como causa de juzgar la imitación imposible:

Estos son los errores que he señalado al principio, cometidos por los príncipes de nuestros tiempos que deben juzgar las cosas grandes, y es por eso que deberían oír cómo se han conducido quienes debieron juzgar antiguamente problemas semejantes. Pero la debilidad de los hombres actuales, causada por su débil educación y por la escasa noticia que tienen de las cosas, hace que consideren en parte inhumanos y en parte imposibles los juicios de los antiguos ${ }^{55}$.

Así pues, la cuestión del desconocimiento de las historias abordada en el proemio del libro primero es abordada nuevamente, no ya como fuente de error para la alabanza de los tiempos antiguos, sino como una ignorancia que impide que las máximas políticas antiguas se presenten como aplicables a los tiempos contemporáneos. En este sentido, este pasaje resulta especialmente relevante en la medida en que Maquiavelo, mediante la expresión "los errores que he señalado al principio" ${ }^{56}$, relaciona la debilidad de la educación y las escasas noticias de los hechos pasados con juzgar imposible la aplicación de las máximas antiguas, de tal modo que conecta con lo esbozado en el proemio al libro primero.

En dicho proemio, el hecho de que en política no se imite a los antiguos tenía su razón fundamental en el desconocimiento de las historias. Sin embargo, según el modo en el que Maquiavelo articula en este otro texto las causas por las cuales se juzga inhumana e imposible la aplicación de las máximas antiguas parece sugerir una cierta igualación entre

\footnotetext{
${ }^{55}$ N. MAQUIAVELO, Discursos, III, 27, 405.

56 Tanto Vivanti, como Bausi e Inglese en sus ediciones de los Discursos entienden que esta referencia conecta este pasaje con el proemio al libro I.
} 
ambos motivos (débil educación ${ }^{57} \mathrm{y}$ desconocimiento de las historias) que no se encontraba en la enunciación mediante una oración subordinada comparativa en el pasaje del proemio al libro primero. Es decir, mientras que en el proemio se aducía el desconocimiento de las historias por encima de la debilidad a que la actual educación había conducido al mundo como la causa principal de que se considere la imitación de los antiguos como imposible (mediante la expresión "non tanto [...] quanto"), en este otro pasaje, se produce una igualación entre los dos motivos.

En suma, consideramos que la polémica anticristiana constituye no una crisis insuperable sobre la imitación de los antiguos (casi relegados a la función del mito), sino por el contrario una condición fundamental que recorre parte de la obra de Maquiavelo y que se encuentra desde el principio cuando se trata el problema de la ausencia de imitación de los antiguos en política.

\section{1 Observaciones críticas de Maquiavelo sobre la imitación}

Tal y como ya hemos señalado, las distintas menciones a la cuestión de la imitación se encuentran mediadas por una crítica negativa a ciertas ideas que impiden considerar la posibilidad de la imitación. Así pues, en los Discursos se parte de una crítica hacia una lectura hedonística de las historias, por la que éstas resultan ser más admiradas que imitadas. De esta manera, Maquiavelo señala la presencia de la imitación de los antiguos tanto en las artes, como en la jurisprudencia y la medicina, frente a su ausencia en el ámbito de la política de modo que, por no extraerse el sentido político de las historias, parece que ésta no sólo es difícil sino imposible:

Considerando entonces todo el honor que se atribuye a la antigüedad, y cómo tantas veces, dejando de lado otros infinitos ejemplos, un fragmento de estatua antigua ha sido comprado a alto precio, para tenerlo consigo, honrar la casa y lograr que lo imiten quienes de ese arte se complacen $[. .$.$] y observando por otro lado cómo las virtuosísimas acciones$

\footnotetext{
${ }^{57}$ En este texto, según la edición crítica de Bausi, todos los manuscritos recogen los términos debole educazione, y no como en el libro I, proemio, donde existe una variación entre manuscritos: la expresión debolezza nella quale la presente religione ha condotto el mondo; es sustituida por debolezza nella qualle la presente educatione ha condotto el mondo. Por este motivo, conectamos la idea de la debilidad de la educación con, como lo hace Bausi, la idea de la debilidad en la educación inculcada por la religión cristiana, la cual será tematizada en detalle en Discursos, II, 2.
} 
que las historias nos muestran, realizadas por reinos y repúblicas antiguas [...] son más rápidamente admiradas que imitadas, y aun, cada uno huye de ellas en cada mínima cosa, hasta el punto de que nada nos ha quedado de aquella antigua virtud, no puedo evitar que ello a la vez me asombre y me duela. Y mucho más en cuanto veo que, en las diferencias civiles nacidas entre los ciudadanos, o en los males en que los hombres caen, siempre se recurre a aquellos remedios que han sido juzgados y ordenados por los antiguos ${ }^{58}$.

El resultado, según Maquiavelo, sería el error de considerar las historias por mero deleite, como si se hubiera producido un cambio en todos los órdenes respecto a los que regían en los tiempos antiguos. Asimismo, la problemática de la imitación de los antiguos se encuentra mediada por la crítica anteriormente referida en la que Maquiavelo contempla que la alabanza puede ser legítima en ciertas ocasiones, de modo que sólo a partir de ciertas condiciones es admisible la pretensión de recuperar los tiempos antiguos:

En todas estas provincias [reino de Francia, el reino de los Turcos, el del Sultán y los pueblos de Alemania], entonces, después de que los Romanos se arruinaran, y en todas esas sectas, ha habido esta virtud y todavía existe en parte de ellas, y es deseada y con verdadera alabanza elogiada. Y, el que nace en aquéllas y elogia los tiempos pasados más que los presentes, podría engañarse pero, el que nace en Italia y en Grecia y no se haya vuelto en Italia ultramontano y en Grecia turco, tiene razón en abominar de sus tiempos y en elogiar los otros, porque en los antiguos hay muchas cosas que los vuelven maravillosos, y en los suyos no hay nada que los recompense de tanta extrema miseria, infamia y vituperio ${ }^{59}$.

Esta observación crítica acerca de la preferencia de los tiempos antiguos sobre los modernos tiene lugar a partir de una consideración de las condiciones políticas de los pueblos, de modo que la alabanza de los tiempos antiguos y la pretensión de su recuperación, lejos de pretenderse de manera utópica ${ }^{60}$ y sin referencias precisas, está mediada por la situación política concreta de cada caso. Maquiavelo introduce, por tanto, la imitación de los antiguos a partir de estas matizaciones:

\footnotetext{
${ }^{58}$ N. MAQUIAVELO, Discursos, I, proemio, 49-50.

${ }^{59}$ N. MAQUIAVELO, Discursos, II, proemio, 207.

${ }^{60}$ Se trata de la máxima de atenerse a la verità effettuale della cosa que Maquiavelo otorga a su análisis en El principe, XV.
} 
No sé entonces si yo mereceré ser incluido entre los que se engañan, si en estos mis discursos elogio demasiado los tiempos de los antiguos Romanos y censuro los nuestros. Y realmente, si la virtud que entonces reinaba y el vicio que ahora reina no fueran más claros que el sol, mi palabra sería más contenida, dudando de no incurrir en este engaño del que acuso a algunos. Pero siendo la cosa tan clara que cualquiera la ve, me animaré a decir manifiestamente lo que comprendo de aquellos tiempos y de estos tiempos, para que los ánimos de los jóvenes que lean mis escritos puedan escapar de éstos y prepararse para imitar aquéllos, cada vez que la fortuna les dé ocasión para hacerlo ${ }^{61}$.

No estamos, pues, ante la preferencia irreflexiva de los tiempos antiguos sobre los modernos, de modo que Maquiavelo pone en relación de manera directa la utilidad de las historias con el problema de la imitación también en El arte de la guerra. Esta noción de imitación de las historias se encuentra unida con la producción misma de Maquiavelo, en el sentido de que él mismo confiere al hecho de escribir las historias un valor fundamental como modo de presentar en esos escritos máximas que resulten aplicables, señalando la necesidad de imitarlas cuando la fortuna lo permita ${ }^{62}$.

\subsection{Constancia antropológico-cosmológica y teoría de la ocasión}

En un estudio crítico sobre la tesis de Koselleck en torno a la fórmula historia magistra vitae, S. Chignola ha apuntado dos cuestiones fundamentales en torno a la historia en Maquiavelo, que merecen ser relacionadas a su vez, al menos a nuestro juicio, con el problema de la imitación:

La utilidad de la historia, la ejemplaridad de esta última, la afirma Maquiavelo a través de un doble registro en el cual aquella es pensada, por un lado, en la forma general de la recurrencia (el constante mutarsi de los tiempos según una revolutio hecha de expansión, culmen y degeneración), y, por otro, como punto de incidencia singular entre virtud y fortuna ${ }^{63}$.

\footnotetext{
${ }^{61}$ N. MAQUIAVELO, Discursos, II, proemio, 208.

${ }^{62}$ N. MAQUIAVELO, El arte de la guerra, VII, en Maquiavelo, Madrid: Gredos, 2011, 244.

${ }^{63} \mathrm{~S}$. CHIGNOLA, "Los conceptos y la historia (Sobre el concepto de historia)", en S. CHIGNOLA; G. DUSO, Historia de los conceptos y filosofía política, Madrid: Biblioteca Nueva, 2009, 266.
} 
Así pues, cabría señalar una primera condición sobre la cuestión de la imitación que Maquiavelo aborda en distintos pasajes como condición necesaria, pero no suficiente, para admitir la posibilidad de imitación de los antiguos; y que pasa por asumir la idea de continuidad en las cosas del mundo y de los hombres, de tal manera que la imitación sólo es posible bajo la idea de repetición entendida no sólo en su aspecto cosmológico, sino también sobre la base de una constante antropológica:

$\mathrm{Y}$, quien examine las cosas presentes y las antiguas, verá fácilmente que, en todas las ciudades y en todos los pueblos, aparecen los mismos deseos y los mismos humores, y que ellos existieron siempre. De modo que, a quien examine con diligencia las cosas pasadas, le resultará fácil prever las futuras en toda república y encontrar para ellas los remedios usados por los antiguos o, si no encontrara los usados, pensar nuevos por la semejanza de las circunstancias. Pero, como estas consideraciones son descuidadas o no comprendidas por los lectores o, si son comprendidas, no son conocidas por quien gobierna, la consecuencia es que, en todo tiempo, suceden los mismos escándalos ${ }^{64}$.

El conocimiento de las cosas modernas y de las antiguas permite (desde la admisión de la constancia de los mismos deseos y pasiones) reconocer coyunturas isomorfas y la aplicación de tácticas y estrategias similares (o nuevas, cuando las antiguas hayan mostrado su inutilidad). Se trata, pues, del principio mismo de conmensurabilidad entre el pasado y el presente, esto es, la suposición de la constancia antropológica y cosmológica, que convierte en operativo el conocimiento de las acciones pasadas ${ }^{65}$. Esta idea es abordada por Maquiavelo también en otros pasajes ${ }^{66}$, de modo que confiere al conocimiento de la relación interna entre pasado y futuro una utilidad política irrenunciable. Por ejemplo, para Florencia hubiera sido conveniente conocer la identidad en las costumbres de los bárbaros:

\footnotetext{
${ }^{64}$ N.MAQUIAVELO, Discursos, I, 39, 151.

${ }^{65} \mathrm{La}$ admisión de las mismas pasiones como condición de posibilidad de la imitación en Maquiavelo es señalada por H. Günther en Geschichtliche Grundbegriffe, aunque estableciendo una línea de continuidad entre la argumentación humanista y la argumentación maquiaveliana al respecto, filiación ésta con la que discrepamos: "Maquiavelo argumenta todavía en el estilo de los humanistas con el concepto de imitación de los ejemplos desde los trabajos históricos, Istorie, de los antiguos, y esto lo posibilita la igualdad de las cualidades esenciales de la naturaleza de los hombres y el resto de las condiciones de la acción" ( $\mathrm{H}$. GÜNTHER, "Geschichte, Historie", en O. BRUNNER, W. CONZE, R. KOSELLECK (hrsg.), Geschichtliche Grundbegriffe: Historisches Lexikon zurpolitisch-sozialen Sprache in Deutschland, Band 2, 1994, 629). ${ }^{66}$ N. MAQUIAVELO, Discursos, III, 43, 440.
} 
También facilita el conocer las cosas futuras por las pasadas, ver que una nación conserva por largo tiempo las mismas costumbres, siendo continuamente avara o fraudulenta, o teniendo algún vicio o virtud semejantes [...] De modo que, si Florencia no hubiera estado obligada por la necesidad, y hubiera leído y conocido las antiguas costumbres de los bárbaros, ni ésta ni muchas otras veces habría sido engañada por ellos, porque éstos siempre han sido los mismos, usando en todos los lados y con todos los mismos procedimientos $^{67}$.

Sin embargo, si tomamos en consideración la cuestión sobre la imitación y la novedad, se encuentra en El príncipe una limitación a esta idea, de modo que, más allá de la diversa naturaleza de los ejemplos aducidos en las distintas obras, se presenta en este texto la segunda condición fundamental para la posibilidad de la imitación. Si partimos en el análisis de la idea defendida en los Discursos, donde Maquiavelo presenta su trabajo como una vía que no ha sido explorada aún por nadie, y que se refiere a la necesidad de imitar en política a los antiguos como se hace en las demás disciplinas, en El príncipe nos encontramos con una particular combinación entre novedad e imitación. En este texto, Maquiavelo presenta la cuestión de la imitación a partir de la consideración "De los principados nuevos que se adquieren mediante las propias armas y por virtud"68. En este fragmento se observa cómo no es posible afirmar la novedad en sentido absoluto, pues siempre se procede por imitación pero ésta, a su vez, se presenta como limitada en el sentido de que resulta imposible alcanzar una imitación completa de las virtudes de quienes se imita. En este pasaje, Maquiavelo señala, con una metáfora similar a la utilizada en los Discursos, la necesidad de impregnarse del aroma de las virtudes a imitar; pero también mediante la metáfora del arquero presenta la imitación como una cuestión que remite a los ejemplos como guías y no como copias exactas del modelo. Se percibe, entonces, como ya señalábamos, desde el principio de sus escritos una cierta reserva por parte de Maquiavelo a la imitación con pretensión de autenticidad o integridad.

Asimismo, frente a aquella primera condición por la que es posible prever las consecuencias futuras a través del conocimiento de los hechos pasados, nos encontramos que Maquiavelo en varios textos introduce matices a esta idea. A este respecto, veíamos

\footnotetext{
${ }^{67}$ N. MAQUIAVELO, Discursos, III, 43, 440-441.

${ }^{68}$ N. MAQUIAVELO, El príncipe, VI, Madrid: Biblioteca Nueva, 2004, 85.
} 
que Maquiavelo contemplaba ${ }^{69}$, sobre la base de la identidad de las costumbres, la posibilidad de que los "remedios" utilizados por los antiguos puedan no estar en uso y, por lo tanto, la necesidad de aplicar unos nuevos. Esta idea que introduce una condición no ya positiva, sino de limitación de las soluciones ofrecidas por los antiguos es retomada por Maquiavelo en El arte de la guerra, de modo que la exhortación a la imitación de los antiguos parte de considerar dignas de ser imitadas únicamente algunas de sus cualidades, de tal manera que nos encontramos ante la presentación de los tiempos antiguos con una doble naturaleza, donde esa observación remite a la posibilidad de dos tipos de lecciones de la misma:

(Fabrizio) Si no temiera ofender, diría mi opinión; y en verdad no lo temo, hablando con amigos, y no para calumniar, sino para discutir las cosas. ¡Cuánto mejor hubieran hecho nuestros antepasados, que en paz estén, procurando la imitación de los antiguos en las cosas rudas y fuertes, y no en el lujo y la molicie; en lo que hacían a la luz del sol, y no en lo realizado a la sombra, tomando las lecciones de la Antigüedad verdadera y perfecta, no de la falsa y corrompida! $!^{70}$ Porque desde que los romanos se aficionaron a los placeres, empezó la ruina de mi patria ${ }^{71}$.

Asimismo, Maquiavelo presenta el problema que supone para la imitación de los antiguos la corrupción de su siglo, de modo que esta imitación queda reducida a aquello que resulte compatible con los tiempos actuales ${ }^{72}$. Es en este texto donde Maquiavelo establece la segunda condición para la posibilidad de la imitación, es decir, la teoría de la ocasión de una manera desarrollada y no sólo mencionada ${ }^{73}$ :

\footnotetext{
${ }^{69}$ N. MAQUIAVELO, Discursos, I, 39, 151.

${ }^{70}$ Nuevamente se observa de manera muy gráfica la recurrencia de la metáfora de la luz en relación con la verdad y la sombra con la falsedad en la obra maquiaveliana.

${ }^{71}$ N. MAQUIAVELO, El arte de la guerra, I, en Maquiavelo, Madrid, Gredos, 2011, 99-100.

${ }^{72}$ N. MAQUIAVELO, El arte de la guerra, I, 101.

${ }^{73}$ En cuanto a otra mención en la obra maquiaveliana que permite relacionar la teoría de la ocasión con la posibilidad de la imitación cabe señalar el proemio al libro segundo de los Discursos: "pero siendo la cosa $\tan$ manifiesta que cualquiera la ve, me animaré a decir manifiestamente lo que comprendo de aquellos tiempos y estos tiempos, para que los ánimos de los jóvenes que lean mis escritos puedan escapar de éstos y prepararse para imitar aquéllos, cada vez que la fortuna les dé ocasión para hacerlo. Porque es deber de hombre bueno enseñarle a otros el bien que por la malignidad de los tiempos y de la fortuna no pudo hacer, para que, siendo muchos los capaces de ello, algunos de los más amados por el Cielo puedan hacerlo" (N. MAQUIAVELO, Discursos, II, proemio, 208).
} 
Cosme - Nada replicaré a lo que acabáis de decir, dejándolo a la consideración de los que fácilmente pueden juzgarlo; y para esclarecer mis dudas, insistiré en preguntaros, ya que acusáis a vuestros contemporáneos de no imitar a los antiguos en las grandes e importantes acciones ¿por qué censuráis que no les parezcan, y al mismo tiempo en la guerra, que es vuestra profesión y tenéis fama de excelente, nada habéis hecho, que se sepa, para imitar a los procedimientos de los antiguos, ni siquiera, asemejarlos?

Fabrizio- [...] Siempre que los hombres quieren hacer alguna cosa, deben prepararse hábilmente para que, llegada la ocasión, puedan realizarla: cuando las preparaciones se hacen cautamente, no se conocen, y a nadie se puede acusar de negligencia si no ha llegado la oportunidad de ejecutar la empresa; pero, al llegar, descúbrese enseguida si no está bien dispuesto o si no había pensado en tal cosa. Como yo no he tenido ocasión alguna para demostrar mis propósitos de restablecer la antigua disciplina en la milicia, ni vos, ni nadie, puede culparme de no haberlo hecho ${ }^{74}$.

El conocimiento de las máximas de los antiguos, por tanto, no es suficiente para llevar a cabo la imitación, como tampoco es suficiente el hecho de que los hombres tengan siempre las mismas pasiones, pues es preciso que se dé la ocasión y la coyuntura propicia para la imitación, de modo que las máximas sin los medios no son realizables:

En cuanto a mí, me quejo del destino, que no debió hacerme saber estas importantes máximas sin darme los medios de realizarlas. Viejo ya, no creo tener ocasión de practicarlas, y por ello os las he explicado ampliamente para que, jóvenes como sois y de elevada posición social, podáis, si os parecen útiles, aprovechar mejores tiempos y el favor de vuestros príncipes para recomendárselas y ayudarles a plantearlas. No temáis ni os desalentéis; esta tierra de Italia parece destinada a resucitar las cosas muertas, como lo ha hecho con la poesía, la pintura y la escultura. No puedo alimentar, en lo que a mí atañe, tales esperanzas por mi avanzada edad. De haberme dado la fortuna en tiempo oportuno la posición necesaria para realizar tan grande empresa, creo que en brevísimo tiempo hubiera probado al mundo cuánto valen las instituciones antiguas, y ensanchado mis dominios gloriosamente o sucumbido sin deshonra ${ }^{75}$.

\footnotetext{
${ }^{74}$ N. MAQUIAVELO, El arte de la guerra, I, en Maquiavelo, Madrid: Gredos, 2011, 101-102.

${ }^{75} \mathrm{~N}$. MAQUIAVELO, El arte de la guerra, VII, 244.
} 
Así pues, a partir de estas consideraciones, nos encontramos que la noción de imitación en Maquiavelo si bien se encuentra asentada sobre la base de una constancia en el orden del mundo y de los hombres, ésta se encuentra mediada por un conocimiento crítico, tanto de los antiguos como de los modernos, que le llevan a considerar la posibilidad de imitación a partir de contar con la ocasión propicia para ello. De esta manera, en tanto que la noción de imitación es referida al ámbito de lo político se encuentra necesariamente con la noción de ocasión como ofrecimiento de la fortuna y, por ende, estrechamente vinculada al par virtud-fortuna.

A modo de conclusión cabría, finalmente, ensayar una respuesta a la cuestión sobre la naturaleza de la concepción maquiaveliana de la historia en el modo en que ésta se presenta a partir del desarrollo del topos y su interna relación con el problema de la imitación. En primer lugar, ha quedado puesto de manifiesto que el uso del término "historias" en Maquiavelo no obedece en ningún caso al uso moderno del mismo, esto es, no se encuentra un sentido unitario y general en la historia que torne lícito reducir el plural al singular como si hubiera una historia que reuniera el sentido de todas las historias singulares. Por el contrario, el uso de "historias" remite en todo caso a las mismas entendidas como narraciones concretas, de modo que el uso plural mayoritario se explica a partir de la remisión a una pluralidad de hechos que cobran sentido en la medida en que pueden ser interpretados como ejemplos en el campo de la política.

Asimismo, el valor de las historias se presenta con significado narrativo y ejemplar en la medida en que contienen ejemplos útiles para la vida política, pero cuya interpretación se encuentra mediada por la consideración de las condiciones políticas del presente. Se trata, por tanto, de la presentación de la fórmula ciceroniana con un sentido que no es moral ni retórico sino eminentemente político, que pone de manifiesto la actualidad política de la historia en la obra maquiaveliana y que es fruto de su planteamiento de la historia como algo inmanente. De este modo, la noción de historia resulta ajena tanto al valor didáctico moralizante conferido por la corriente humanista, como también respecto a la noción cristiana de la historia como construcción guiada por la providencia divina. Por un lado, se rechaza una lectura erudita o meramente hedonística de la historia; por el otro, la proyección política de las historias sólo es posible a partir de una lectura "sensata" de las mismas, que permita la traducción contemporánea de coyunturas y situaciones del pasado. 
Así pues, la operatividad del topos ciceroniano se circunscribe a la utilidad que reporta la imitación de los ejemplos antiguos en el ámbito político moderno. En este sentido, Maquiavelo supone una original tematización del problema, en la medida en que él mismo insiste en que el saber antiguo es utilizado en el ámbito de diversas disciplinas (medicina, jurisprudencia, arte), pero no en el ámbito de la política. Ahora bien, si el saber político encuentra algún fundamento en las historias antiguas, ello sólo es factible porque el tiempo cristiano es entendido como un periodo homogéneo respecto al antiguo; es decir, en la medida en que ni la providencia divina ni la gracia cristiana son operativas. Por otro lado, Maquiavelo insiste en presentar su propuesta como una vía novedosa y nunca antes explorada por nadie, pero cuya novedad no se refiere únicamente a nuevas formas de leer las historias, sino al propio uso de una razón política (basada en la experiencia contemporánea) que en ciertos puntos no duda en oponerse, como hemos visto, a la tradición y a la opinión común. En cualquier caso, la cuestión de la imitación se encuentra atravesada por diversas observaciones críticas que en Maquiavelo tienen fundamentalmente como metro la situación contemporánea de la misera Italia y, en particular, la historia de Florencia entendida como contramodelo.

Por último, la fusión entre pasado y futuro, señalada por Koselleck como una de las notas propias de la historia como magistra vitae, está especialmente puesta de manifiesto en la presentación de la problemática de la imitación. Así pues, consideramos que ante la afirmación de una línea de continuidad entre futuro y pasado, en la obra de Maquiavelo esta continuidad no obedece a una mera reproducción de lo mismo, de modo que lo ocurrido en el pasado sea repetible sin más en el futuro. Esto es, al abordar el sentido del topos, nos encontramos con la cuestión de la imitación como modo de hacer efectiva la ejemplaridad de las historias, de tal manera que, si bien la afirmación de una naturaleza invariable se erige como condición de posibilidad de la imitación, ésta no se plantea como ilimitada debido a la necesidad de la confluencia de virtud y fortuna como condiciones fundamentales para su realización, donde la teoría de la ocasión cumple un papel fundamental, pues el éxito no sólo depende del conocimiento de las máximas a imitar sino de lo requerido por las circunstancias. Se trata, pues, de la presentación de la realidad histórico-política como estando siempre en movimiento, y no como una e inmutable. En definitiva, encontramos en Maquiavelo una afirmación crítica del lugar común en la medida en que no se limita a la mera reproducción de un topos sino que, junto con el 
criterio de su experiencia contemporánea, y presentando el problema de la imitación desde una postura que podríamos denominar ecléctica, constituye la fuente misma de su producción teórica denominada por él mismo como arte dello stato. 